"We've been very vocal with the department and with its medical contractor about the need to get a protocol in place and to bring these new medications online," Thompson told Nature Medicine.

In a July 2012 letter, Lawrence Weiner, assistant deputy commissioner for the Massachusetts Department of Correction's Clinical Services Division, wrote that the state was considering adopting practices that match the federal guidelines and noted that the University of Massachusetts Medical School in Worcester, which oversees inmate health care, had committed to completing the new protocol by the end of that month. At press time, however, the revision had not yet been completed, according to Diane Wiffin, a Department of Correction spokesperson. Because of the high cost of the newer agents, "there is an enormous incentive to make this move as slowly as possible," Thompson says.

A 2011 report on inmate healthcare costs commissioned by the Massachusetts Department of Correction suggested that one way to cut medication costs would be to offer inmates who require hepatitis $\mathrm{C}$ treatment the older medications initially and save the new drugs for inmates who don't respond within the first 12 weeks.

\section{Treatment options going south}

Texas, the state with the largest prison population in the US, hasn't yet made the drugs available to its inmates, either. "We're working on our guidelines right now for these newer therapies," says UTMB's Murray. The protease inhibitors must be administered every eight hours with a snack. Given those requirements, Murray says it may make sense to create special hepatitis $\mathrm{C}$ treatment facilities. The committee charged with developing the new guidelines, which includes representatives from UTMB as well as the Texas Department of Criminal Justice, is considering all these possibilities. In the meantime, Murray says, UTMB physicians have restricted the number of new inmates starting the older two-drug therapy. The need for treatment is rarely urgent, he says. "There is no reason to put patients on suboptimal therapy."

Inmates in Georgia are in a similar situation, according to Anne Spaulding, an infectious disease physician at Emory University's Rollins School of Public Health in Atlanta who was hired in 2003 by the Georgia Department of Corrections to care for inmates with hepatitis C. "I was told I could use the new antivirals when they came out," she says. But even after the new drugs were approved, Spaulding couldn't access them. "I kept on being strung along," she says.

Spaulding says she developed a protocol for the use of the medications, but it was never implemented. It's not clear whether any inmates in Georgia are taking the protease inhibitors today. Spaulding was let go earlier this year due to budget cuts. At that time, the medications were not available, she says. Dabney Weems, a spokesperson for the Georgia Department of Corrections, declined to say whether the new drugs are being used. She wrote in an email that all inmates "receive individualized care based on their patient factors."

For inmates such as Proulx, who couldn't be cured by the old regimen, these new drugs may mean the difference between life and death. "I worry if I do not get treatment in the near future, my condition will worsen," he wrote last year in a letter to the Massachusetts Department of Public Health. "I should not be denied medical treatment when the drugs to treat [my] condition are available, based on my status as a prisoner."

Thompson agrees. He and his colleagues have already talked about filing a lawsuit if they don't see progress. "There is no shortage of clients willing to participate if that's what it takes to get triple therapy implemented," he says.

Cassandra Willyard

\title{
Group purchasing plan launched to save on research supplies
}

For most shoppers, buying in bulk means stocking up at big-box retailers such as Costco and Walmart to save on groceries and other household goods. But the discounts found in bulk shopping go well beyond the home. For more than 30 years, hospitals have banded together to purchase expensive drugs at discounted rates. Now, a new effort has brought together academic research centers for a similar savings.

Companies such as Texas-based Novation have long provided what's known as group purchasing options (GPOs) for hospitals. But the supplies needed by basic biomedical research teams at academic medical institutions differ from those used by clinicians. To fill the gap, a group representing academic hospitals, the Academy for Medical Development and Collaboration (AMDeC), has created a GPO to enable its members to combine their purchasing power to yield savings on essential lab supplies.

According to Maria Mitchell, who has served as president and chief executive of AMDeC since its inception in 1997, the organization is uniquely qualified to head the new GPO operation, which was approved by its board late last year and in August closed its first purchasing deal with GenScript, a supplier in Piscataway, New Jersey, that produces reagents and other key lab necessities. It's a first for GenScript as well: although the company has worked with some large companies in the past on big orders, "this is the first time" that the company has made a purchasing agreement with a GPO, says Frank Zhang, its chief executive.

\section{A penny-wise proposition}

Unlike hospital GPOs, which focus on frequently used drugs and hospital equipment, AMDeC's GPO will focus more on "reagents, primers [and other] things that are used in laboratories day in and day out," Mitchell says. The labs of AMDeC members typically spend a total of $\$ 400$ million on these products annually, but if they take full advantage of the GPO, they stand to save around $10 \%$ of these costs, says Mitchell.

AMDeC is primarily made up of New York-based institutions such as New York University's Langone Medical Center and the Memorial Sloan-Kettering Cancer Center, but it has expanded to include medical labs affiliated with Rutgers, the State University of New Jersey, and it hopes to become nationwide, according to Mitchell. All institutions already a part of AMDeC are invited to participate in the GPO, and Mitchell estimates that $90-95 \%$ of them will do so.

The move is particularly important given that funding for research, whether through hospital budgets, philanthropic organizations or government grants, has decreased because of the poor economy, says Mitchell. Research-focused hospitals must "spend their dollars where they need them and not invest in the profit margins of companies" by overpaying for supplies.

GPOs have come under government scrutiny before because they can become large enough that they are able to dictate the market, edging toward a monopoly, says Einer Elhauge, a professor at Harvard Law School in Cambridge, Massachusetts. But Elhauge says that there is no reason not to launch one for basic biomedical labs looking for savings: "GPOs can be efficient and procompetitive when they do not command such a big share of the market as to have [illegal] market power."

Susan Matthews 